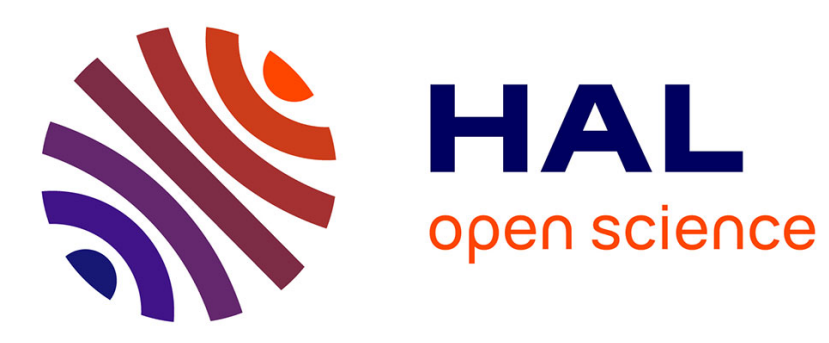

\title{
On the dispersion of solid particles in a liquid agitated by a bubble swarm
}

Thomas Bonometti, Jacques Magnaudet, Pascal Gardin

\section{To cite this version:}

Thomas Bonometti, Jacques Magnaudet, Pascal Gardin. On the dispersion of solid particles in a liquid agitated by a bubble swarm. Metallurgical and Materials Transactions B, 2007, vol. 38B, pp. 739-750. 10.1007/s11663-007-9085-7 . hal-00862695

\section{HAL Id: hal-00862695 \\ https://hal.science/hal-00862695}

Submitted on 17 Sep 2013

HAL is a multi-disciplinary open access archive for the deposit and dissemination of scientific research documents, whether they are published or not. The documents may come from teaching and research institutions in France or abroad, or from public or private research centers.
L'archive ouverte pluridisciplinaire HAL, est destinée au dépôt et à la diffusion de documents scientifiques de niveau recherche, publiés ou non, émanant des établissements d'enseignement et de recherche français ou étrangers, des laboratoires publics ou privés. 


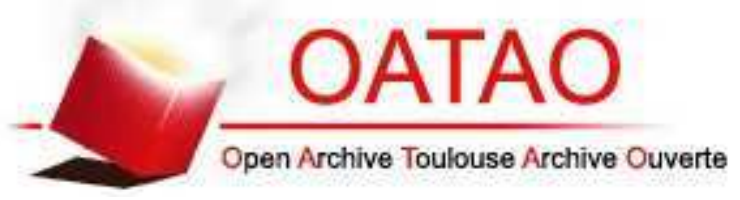

\section{Open Archive TOULOUSE Archive Ouverte (OATAO)}

OATAO is an open access repository that collects the work of Toulouse researchers and makes it freely available over the web where possible.

This is an author-deposited version published in : http://oatao.univ-toulouse.fr/ Eprints ID : 9407

To link to this article : DOI:10.1007/s11663-007-9085-7

URL : http://dx.doi.org/10.1007/s11663-007-9085-7

To cite this version : Bonometti, Thomas and Magnaudet, Jacques and Gardin, Pascal. On the dispersion of solid particles in a liquid agitated by a bubble swarm. (2007). Metallurgical and Materials Transactions B, vol. 38B ( $\left.{ }^{\circ} 5\right)$. pp. 739-750. ISSN 1073-5615

Any correspondance concerning this service should be sent to the repository administrator: staff-oatao@ listes-diff.inp-toulouse.fr 


\title{
On the Dispersion of Solid Particles in a Liquid Agitated by a Bubble Swarm
}

\author{
THOMAS BONOMETTI, JACQUES MAGNAUDET, and PASCAL GARDIN
}

This article deals with the dispersion of solid particles in a liquid agitated by a homogeneous swarm of bubbles. The scale of interest lies between the plant scale (of the order of the tank) and the microscale (less than the bubble diameter). The strategy consists in simulating both the twophase flow of deforming bubbles and the motion of solid particles. The evolution of the spatial distribution of particles together with the encounter and entrainment phenomena is studied as a function of the void fraction and the relative size and mass of particles. The influence of the shape of the bubble and of the model of forces that govern the motion of particles is also considered.

\section{INTRODUCTION}

THE capture of solid particles by bubbles in liquid solutions is a phenomenon of importance in many industrial practices such as mineral processing, petrochemical refining, paper manufacturing, and waste water treatment. In addition, flotation can be used to promote the suspension and dispersion of solids in the liquid phase. When dispersed in a suspension, the activity of solids increases; they are either acting as a catalyst or undergoing a chemical reaction. This is why three-phase flows are also used in industrial catalytic processes, biological waste water treatment, and bacterial leaching processes ${ }^{[1,2]}$ In practice, it has been found that flotation is a complex process affected by numerous factors, such as particle-bubble surface chemistry, particle-bubble size, hydrophilic and hydrophobic properties of surfaces, electrostatic interactions, and hydrodynamic conditions.

Two approaches are generally used to handle this problem. The first of these is to consider the full system and to study the influence of the global parameters (liquid and gas flow rates, chemical composition, and nature of particles) on the overall flotation efficiency. ${ }^{[3-6]}$ The other approach focuses on the simplified system of one or few particles interacting with a single bubble. ${ }^{[7-14]}$ The modeling of the flotation process is based on three elementary microprocesses, namely, the bubble-particle encounter collision, ${ }^{[15-21]}$ the subsequent attachment, ${ }^{[19,22-25]}$ and the detachment. ${ }^{[17,26,27]}$ The aim of

THOMAS BONOMETTI, Postdoctoral Associate, is with the Department of Mechanical and Aerospace Engineering, University of Florida, Gainesville, FL 32611. Contact e-mail: thomas.bonometti@ imft.fr JACQUES MAGNAUDET, Research Director, is with the Institut de Mécanique des Fluides de Toulouse, UMR CNRS/INPT/ UPS, 5502, Allée Camille Soula 31400 Toulouse, France. PASCAL GARDIN, Technical Manager, is with the Process Engineering Department, Arcelor Research, Voie Romaine, BP30320, 57283 Maizières-lès-Metz Cedex, France. the modeling of the flotation at this microprocess scale is to predict the global efficiency probability that can be used to size full plants.

The ultimate purpose of this study is to obtain a better understanding of inclusion interaction with argon bubbles rising in liquid steel, taking into account interactions of bubbles as they occur in many steelmaking processes, such as ladle or continuous casting mould. The efficiency of inclusion entrapment by argon bubbles was already investigated by different authors. ${ }^{[28,29]}$ The main conclusion is that an optimum bubble size could be obtained, but studies are restricted to single spherical bubbles. In the present study, the scale under consideration lies between the macroscopic plant scale and the microprocess scale. Our approach consists of investigating the motion and dispersion of solid particles in a liquid agitated by rising bubbles, which have spherical, spheroidal, or spherical cap shapes. Figure 1 shows a sketch of the situation investigated: in-line deforming bubbles rise and modify the motion of smaller solid particles present in the liquid. The bubble initial diameter is $D$ and the distance between two bubble centroids is $H$.

This numerical study consists of the simulation of a two-dimensional axisymmetric homogeneous bubbles suspension using a volume of fluid (VOF) method together with the computation of solid particles by means of Lagrangian tracking. We assume that the particles (1) have no effect on the fluid (one-way coupling), (2) are spherical, and (3) are small compared to the bubbles. No model is introduced to take into account possible particle collisions, and particles are allowed to overlap. The methodology is as follows: we first compute the rise of a homogeneous suspension of bubbles, without any particle. The simulation is stopped as soon as bubbles have reached a stationary shape and velocity. Then we set up a uniform distribution of monodisperse particles initially at rest and start the simulation again by using the results of the first computation as an initial flow field. Note that the velocity of the suspension is constant within 5 pct during the particle-bubble simulation. 


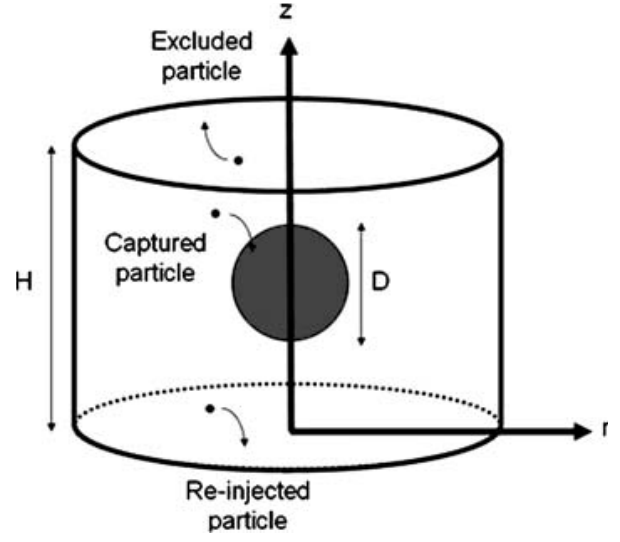

Fig. 1-Computational domain and possible particle paths. The bubble is at the center of the domain.

The fixed parameters are the physical properties of the gas-liquid flow; i.e., the density ratio $\rho_{l} / \rho_{\mathrm{g}}=17,000$, the viscosity ratio $\mu_{l} / \mu_{\mathrm{g}}=100$, the Bond number $\mathrm{Bo}=$ $\rho_{l} \mathrm{~g} D^{2} / \sigma=1$, and the Morton number Mo $=\mathrm{g} \mu_{l}^{4} /$ $\rho_{l} \sigma^{3}=5 \times 10^{-8}$. In these expressions, $\rho_{l}$ and $\rho_{g}$ are the density of the liquid and gas, respectively; $\mu_{l}$ and $\mu_{g}$ are the corresponding dynamical viscosities; $g$ denotes gravity; $D$ is the bubble diameter; and $\sigma$ is the surface tension. These choices allow us to compute the rise of ellipsoidal bubbles, the Reynolds number of which (based on the terminal velocity) is $O(100)$. Note that most bubbles in continuous casting molds are ellipsoidal. ${ }^{[29]}$ The influence of the bubble shape will be discussed in Section III-D. We vary the volume fraction of the gas $\alpha=2 D^{3} / 3 H^{3}$ from 0.7 to 17 pct, the density of the particles $\rho_{p}$ from $0.1 \rho_{l}$ to $\rho_{l}$ (for a prescribed particle diameter), and the particle diameter $d_{p}$ (for a prescribed $\rho_{p}$ ), so that the particulate Reynolds number $\operatorname{Re}_{p}=\rho_{l}\left(\rho_{l}-\rho_{\mathrm{g}}\right) \mathrm{g} d_{p}^{3} / 18 \mu_{l}^{2}$ varies from $10^{-4}$ to 5 . The $\operatorname{Re}_{p}$ is calculated a priori by taking as characteristic velocity $U_{p}$, the sedimentation velocity of a solid particle under creeping flow conditions, i.e., $U_{p}=\left(\rho_{\digamma} \rho_{p}\right) \mathrm{g} d_{p}^{2} / 18 \mu_{l}$. We choose this range of parameters in order to follow most closely the industrial conditions used in metallurgical flotation, as shown in Table I. Also shown in Table I are the parameters used in the study of Zhang and co-workers ${ }^{[29]}$ representing typical spherical inclusions, such as alumina in molten steel.

Table I. Comparison of the Parameters Investigated in the Study of Zhang et al. and the Present Study

\begin{tabular}{lll}
\hline Studies & Zhang et al. ${ }^{[29]}$ & $\begin{array}{c}\text { Present } \\
\text { Study }\end{array}$ \\
\hline $\begin{array}{l}\text { Density ratio between the } \\
\text { liquid and the gas, } \rho_{l} / \rho_{g}\end{array}$ & 4300 & 17,000 \\
$\begin{array}{l}\text { Density ratio between the } \\
\text { particles and the liquid, } \rho_{p} / \rho_{l}\end{array}$ & 0.4 & 0.1 to 1 \\
$\begin{array}{l}\text { Flow Reynolds number, Re } \\
\text { Particle Reynolds number, } \mathrm{Re}_{p}\end{array}$ & $\begin{array}{l}100 \text { to } 3000 \\
\text { Bond number, Bo }\end{array}$ & $\approx 100$ \\
$\begin{array}{l}\text { Morton number, Mo } \\
\text { Mon to } 0.6\end{array}$ & $\begin{array}{l}10^{-4} \text { to } 5 \\
1\end{array}$ \\
\hline
\end{tabular}

The computations allow us not only to follow the time evolution of the particle distribution, but also to perform statistics on the rate of elimination of particles. A first statistic deals with the bubble-particle encounter interaction. Indeed, when a particle is located in a region in which the local volume fraction of the gas is larger than 0.5 , we arbitrarily denote this particle as "encountered" (there is a collision). By counting the number of encountered particles, we can build an "encounter efficiency" $E_{\text {coll }}$ equal to the ratio of the number of encountered particles over the initial number of particles in the domain. Note that $E_{\text {coll }}$ is different from the classical collision efficiency, ${ }^{[30]}$ because the latter makes use as a denominator of the number of particles initially located along the bubble trajectory. A second statistic deals with particles that are driven by the liquid to the top of the domain. When a particle crosses the upper boundary, it is denoted as "entrained." We then define an "entrainment efficiency" $E_{\text {entr }}$, equal to the ratio of the number of particles that cross the upper boundary over the initial number of particles. The two efficiencies $E_{\text {coll }}$ and $E_{\text {entr }}$ allow us to disentangle the contribution of the bubble-particle encounter and that of the entrainment of particles by the liquid in the overall flotation process.

\section{EQUATIONS AND NUMERICAL TREATMENT}

\section{A. Simulation of the Bubble Swarm}

The bubble swarm is computed through a VOF method without interface reconstruction. In particular, we solve the one-fluid Navier-Stokes Eq. [1], assuming the two fluids to be Newtonian and incompressible, with uniform surface tension and no phase change.

$$
\begin{aligned}
\frac{\partial U}{\partial t}+U \cdot \nabla U= & -\frac{1}{\rho} \nabla P+g+\frac{1}{\rho} \nabla \cdot\left[\mu\left(\nabla U+{ }^{t} \nabla U\right)\right] \\
& -\frac{\sigma}{\rho}(\nabla \cdot n) n \delta_{I} ; \nabla \cdot U=0
\end{aligned}
$$

In Eq. [1], $U, P, \rho$, and $\mu$ are the local velocity, pressure, density, and dynamical viscosity in the flow, respectively; $g$ denotes gravity; and $\sigma$ is the surface tension. The surface delta function $\delta_{I}$ is zero outside the interface, the unit normal of which is denoted by $n$. The position of the bubble surface is updated by solving the transport Eq. [2], which governs the local volume fraction of the gas.

$$
\frac{\partial C}{\partial t}+U \cdot \nabla C=0
$$

This volume fraction equals one (respectively, zero) in cells filled with gas (respectively liquid) and takes intermediate values in cells belonging to the transition region. The local density and dynamical viscosity are evaluated using a linear interpolation, namely, $\rho=C \rho_{g}+(1-C) \rho_{1}$ and $\mu=C \mu_{g}+(1-C) \mu_{1}$. The capillary force is modeled using the continuum surface force model. ${ }^{[31]}$ Equations [1] and [2] are solved using 
the JADIM code developed in our group. Briefly, the momentum equations are discretized on a staggered orthogonal grid using a finite volume approach. The spatial discretization is performed using second-order centered differences. Time advancement is achieved through a third-order Runge-Kutta method for advective and source terms and a Crank-Nicolson method for viscous stresses. Incompressibility is satisfied at the end of each time-step through a projection method. The overall algorithm is second-order accurate in both time and space. Details on the spatial discretization and timeadvancement algorithm used in this code may be found in Reference 32.

\section{B. Particle Tracking}

The hydrodynamic interaction between a particle and a bubble is investigated by means of the following extended Basset-Boussinesq-Oseen Eq. [3].

$$
\begin{aligned}
m_{p} \frac{d V}{d t}= & \rho_{f} C_{D} \frac{\pi d_{p}^{2}}{8}|U-V|(U-V)+\left(m_{p}-m_{f}\right) g \\
& +\left\{\left.m_{f} C_{M} \frac{D U}{D t}\right|_{p}-m_{f} C_{M} \frac{d V}{d t}\right\}+\left.m_{f} \frac{D U}{D t}\right|_{p}
\end{aligned}
$$

Here, $m_{p}$ and $m_{f}$ are the mass of the particle and the mass of the same volume of liquid, respectively; $V$ is the particle velocity; $U$ is the velocity of the liquid at the particle location; $\rho_{f}$ and $\mu_{f}$ are the density and dynamical viscosity of the liquid, respectively; $C_{M}$ is the added mass coefficient (here, $C_{M}=1 / 2$ ); and $d_{P}$ is the particle diameter. In Eq. [3], $\left.\frac{D U}{D t}\right|_{p}$ stands for the material derivative $\left.\frac{D U}{D t}\right|_{p}=\frac{\partial U}{\partial t}+\left.U \cdot \nabla U\right|_{x=x_{p}}$, whereas $\frac{d V}{d t}$ is the time derivative of $V$ following the corresponding particle. The drag force coefficient is calculated using Schiller and Nauman's model: ${ }^{[33]}$

$$
C_{D}=\frac{24}{\operatorname{Re}}\left(1+0.15 \mathrm{Re}^{0.687}\right) \quad \text { with } \quad \operatorname{Re}=\frac{\rho_{f} d_{p}|U-V|}{\mu_{f}}
$$

We assume that lift and history effects are negligible compared to drag and added mass effects. Nevertheless, effects of the lift force will be discussed in the Appendix.

\section{Numerical Setup}

The computations are axisymmetric and are performed within a cylindrical $(r, z)$ domain $0.5 \mathrm{H} \times H$ large. We use a regular grid spacing in the $r$ - and $z$-directions $\left(\Delta r / D=\Delta z / D=1.10^{-2}\right)$. Free-slip boundary conditions are imposed on the lateral boundaries; the top and bottom boundaries are assumed to correspond to periodic conditions. This choice is a key point for the computation of an infinite chain of bubbles, because it allows us to compute only one element of the chain, i.e., a domain containing only one bubble. Table II indicates the grid resolution and the number of particles used for the entire range of void fractions (the number of particles per unit of volume is kept constant). The void fraction is defined as the ratio between the volume of gas inside the computational domain over the volume of the computational domain.

\section{Assumption of Axisymmetry}

By performing axisymmetric computation, we assume the particles' trajectories to be restricted into radial planes. To check whether this assumption is realistic, we performed a fully three-dimensional computation of the particular configuration corresponding to $\alpha=17 \mathrm{pct}$, $\rho_{p}=0.36 \rho_{l}$, and $\operatorname{Re}_{p}=5$. Figures 2(a) and (b) show the bubble-particle distribution at a specific time and a vertical view of the particles' location at several times (from $t(g / D)^{1 / 2}=0$ to 0.9 ), respectively. Here, all the boundaries are submitted to periodic conditions, so that this computation reproduces the rise of a homogenous swarm of bubbles. We can see from Figure 2(a) that with this choice of parameters, the bubble has an oblate spheroidal shape. It is clear from Figure 2(b) that particle trajectories are confined to planes that are mostly parallel to the local radial direction, at least far from the outer boundaries. Note that during the time of the simulation, the bubbles were rising straightly. Axisymmetric computations are, therefore, relevant in the case of a swarm that rises rectilinearly.

\section{E. Preliminary Checking}

This section focuses on some numerical tests aimed at showing the sensitivity of the results to numerical parameters. We first investigated whether the number of particles used for the computation was sufficient to obtain reliable results. For example, we performed three computations, with 98, 392, and 882 particles. The other parameters were $\alpha=17$ pct, $\rho_{p}=0.36 \rho_{l}$, and $\operatorname{Re}_{p}=5$. Figure 3 shows the evolution of $E_{\text {coll }}, E_{\text {entr }}$, and ( $E_{\text {coll }}+$ $\left.E_{\text {entr }}\right)$. Time is scaled by $V_{T} / D, V_{T}$ is the terminal velocity of the bubble swarm, and $D$ is the bubble diameter (Table III for the values of $V_{T}$ ). The terminal velocity $V_{T}$ is defined through

$$
V_{T}(t)=\frac{\int_{\vartheta} C(x, t) U(x, t) \cdot \mathbf{e}_{\mathbf{z}} d \vartheta}{\int_{\vartheta} C(x, t) d \vartheta}
$$

\begin{tabular}{|c|c|c|c|c|c|}
\hline Void Fraction, $\alpha$ & $0.7 \mathrm{pct}$ & $2.1 \mathrm{pct}$ & $6 \mathrm{pct}$ & $11 \mathrm{pct}$ & 17 pct \\
\hline $\begin{array}{l}\text { Grid resolution, } n_{r} \times n_{z} \\
\text { Number of particles in the computational domain }\end{array}$ & $\begin{array}{l}225 \times 450 \\
800\end{array}$ & $\begin{array}{l}160 \times 320 \\
392\end{array}$ & $\begin{array}{l}115 \times 230 \\
200\end{array}$ & $\begin{array}{l}95 \times 190 \\
128\end{array}$ & $\begin{array}{l}80 \times 160 \\
98\end{array}$ \\
\hline
\end{tabular}

where $C$ is the gas volume fraction, $\mathbf{e}_{\mathbf{z}}$ is the unit vector in the vertical direction, and $\vartheta$ denotes the volume of the

Table II. Grid Resolution and Number of Particles Used in the Simulations 


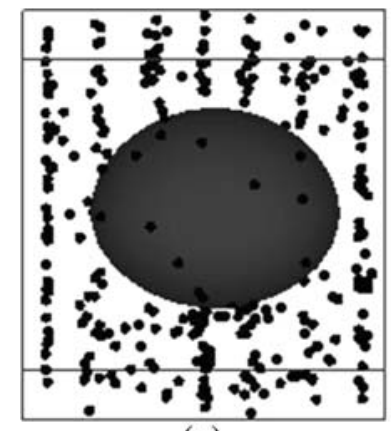

(a)

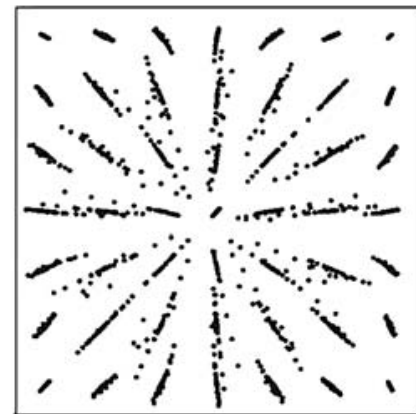

(b)

Fig. 2-(a) Bubble-particle distribution at a specific time and $(b)$ vertical view of the particle location for several time-steps $\left(\right.$ from $t(g / D)^{1 / 2}=0$ to 0.9$)$.

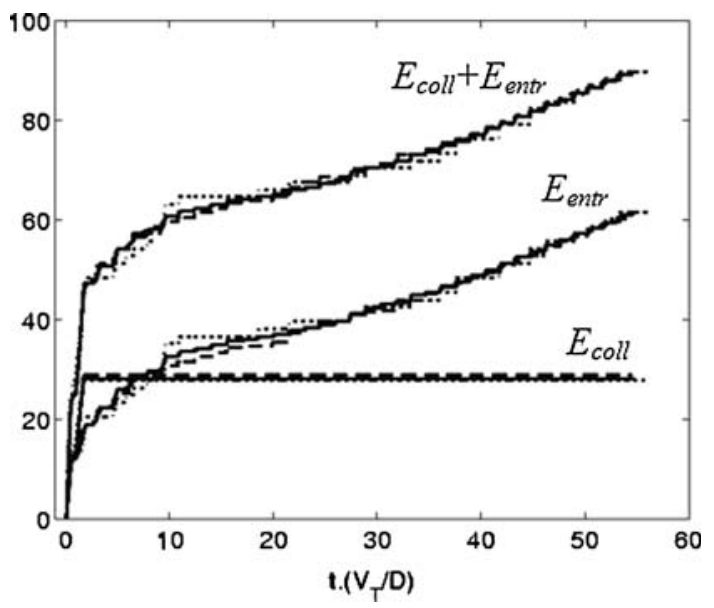

Fig. 3-Influence of the number of particles on efficiencies $(\alpha=17$ pct, $\rho_{p}=0.36 \rho_{l}$, and $\left.\operatorname{Re}_{p}=5\right)$. Time is scaled by $V_{T} / D$. ( $\longrightarrow 882$ particles; (- - . - -) 392 particles; and (.....) 98 particles. The efficiencies are in indicated in percents.

Table III. Evolution of the Velocity of the Bubble Swarm and of the Liquid Velocity with the Void Fraction; $V_{\text {liq }}$ is the Mean Vertical Velocity in the Liquid

\begin{tabular}{llllll}
\hline$\alpha$ & $0.7 \mathrm{pct}$ & $2.1 \mathrm{pct}$ & $6 \mathrm{pct}$ & $11 \mathrm{pct}$ & $17 \mathrm{pct}$ \\
\hline$V_{T} /(g D)^{1 / 2}$ & 2.26 & 2.12 & 1.76 & 1.44 & 1.17 \\
$V_{\text {liq }} / V_{T}$ & 0.002 & 0.007 & 0.030 & 0.074 & 0.118 \\
\hline
\end{tabular}

entire computational domain. This scaling allows us to compare the evolution of the statistics for a reference displacement length of the bubble swarm. For example, the bubbles have crossed a distance of 30 bubble diameters at $t V_{T} / D=30$, whatever the velocity of the swarm. The evolution of $E_{\text {coll }}, E_{\text {entr }}$ and $\left(E_{\text {coll }}+E_{\text {entr }}\right)$ is mostly independent of the number of particles. This is expected, because no collision is taken into account.

We then looked at the influence of the position of the bubble in the domain at the beginning of the computation. Defining $z_{0}$ as the position of the bubble centroid at $t=0$, we ran two simulations with $z_{0} / H=0$ and $z_{0} /$ $H=0.5$, respectively. The other parameters were $\alpha=0.7$ and 17 pct (the two limit cases), $\rho_{p}=0.36 \rho_{l}$, and $\operatorname{Re}_{p}=5$. Figure 4 shows the evolution of $E_{\text {coll }}, E_{\text {entr }}$ and $\left(E_{\text {coll }}+E_{\text {entr }}\right)$. The comparison of $E_{\text {coll }}, E_{\text {entr }}$ for the two cases shows differences that are less than 4 pct. The overall efficiency $\left(E_{\text {coll }}+E_{\text {entr }}\right)$ appears to be independent of the initial position of the bubble.

\section{RESULTS AND DISCUSSION}

\section{A. Influence of the Particle Size}

In this section, we focus on the influence of the size of the solid particles on their motion and on the flotation process. Figure 5 shows the time evolution of the spatial distribution of particles with two different sizes. The Reynolds number of the particles shown in Figure 5(a) is $\mathrm{Re}_{p}=5$; for the particles in Figure 5(b), $\mathrm{Re}_{p}=10^{-4}$. In the first case, particles quickly go away from the bubble wake $\left(0<t V_{T} / D<21\right)$ and remain in the lateral part of the domain $\left(t V_{T} / D>21\right)$. In the second case, the number of particles in the bubble wake decreases with time, but is nonzero (the last view in Figures 5(a) and (b)). Particles are more dispersed in the latter case. Therefore, the phenomenon observed in Figure 5(a) appears to be an effect related to particle inertia.

To confirm this point, we record the mean value of all forces acting on the particles. For each particle, we calculate the norm of the drag, gravitational, and addedmass force and take the corresponding mean value over the total number of particles. The gravitational force is calculated using the difference between the particle density and the density of the local fluid. The evolution is plotted in Figure 6 for two sets of particles $\left(\operatorname{Re}_{p}=5\right.$ and $\left.\operatorname{Re}_{p}=10^{-4}\right)$. After a few time-steps, the added-mass force found for $\operatorname{Re}_{p}=5$ increases to a mean value about 20 pet higher than the drag and gravitational forces (Figure 6(a), $0<t V_{T} / D<10$ ). It then decreases to a value of the same order as the other two forces. Note that between $t V_{T} / D=10$ and $t V_{T} / D=20$, all the particles get away from the bubble wake. This suggests that added-mass effects play a role in the migration of the particles out of the bubble wake. The drag and gravitational forces exhibit periodic oscillations around the same constant mean value, which is about $\left|\rho_{p}-\rho_{l}\right| \mid$ $\rho_{p}$, approximately. Note that we observe the same oscillation in the evolution of the added-mass force. The 


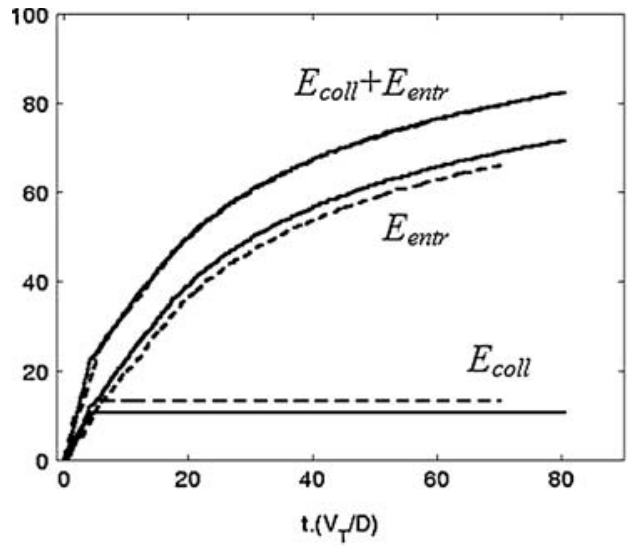

(a)

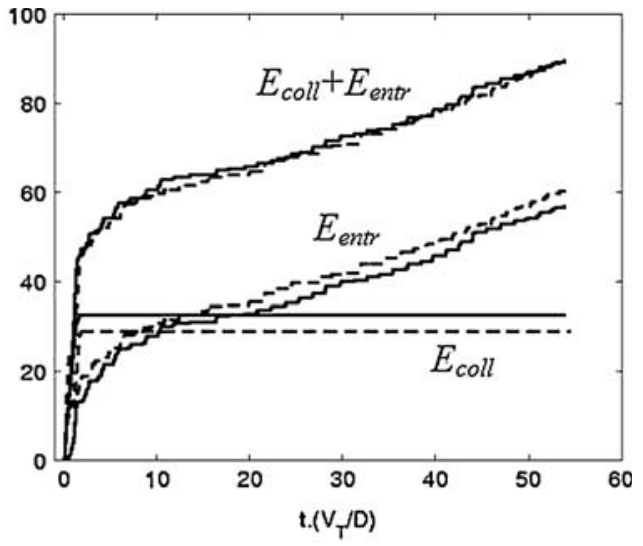

(b)

Fig. 4-Influence of the initial position of the bubble on efficiencies: $(a) \alpha=0.7$ pct and $(b) \alpha=17$ pct $\left(\rho_{p}=0.36 \rho_{l} ; \operatorname{Re}_{p}=5\right)$. ( -$) z_{0} / H=0$; and (- - - - -) $z_{0} / H=0.5$. The efficiencies are indicated in percents.
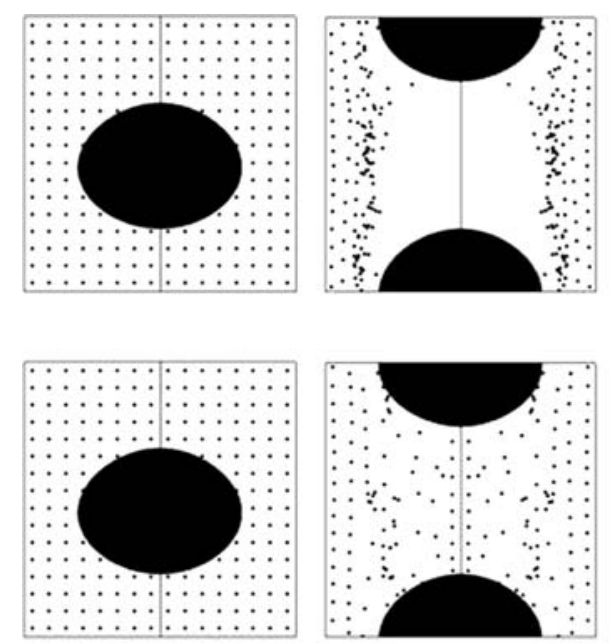

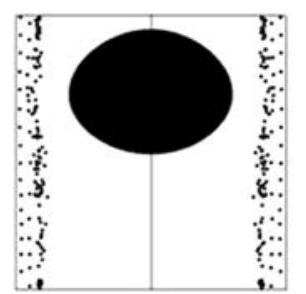

(a)

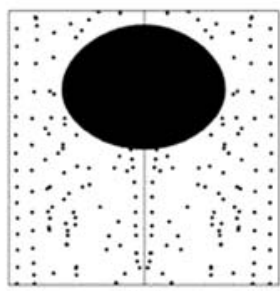

(b)
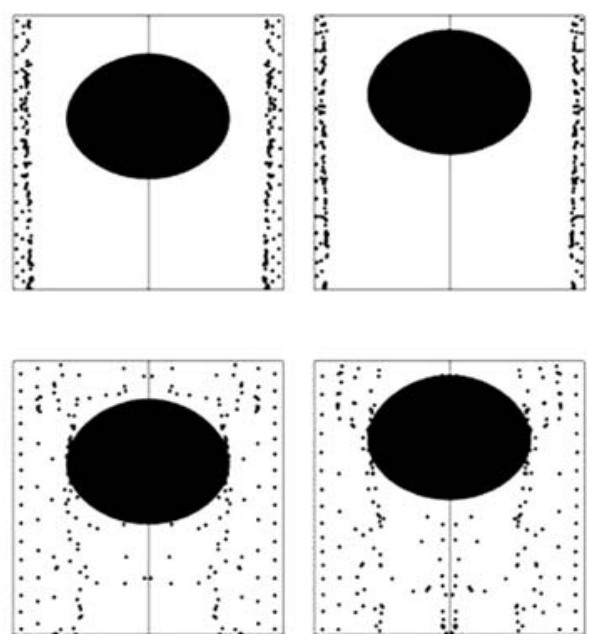

Fig. 5-Effect of the size of particles on efficiencies: evolution of the spatial distribution of particles $\left(\alpha=11\right.$ pct; $\left.\rho_{p}=0.36 \rho_{l}\right):(a)$ Re $e_{p}=5$ and (b) $\operatorname{Re}_{p}=10^{-4}$. The time interval between successive views is $t V_{T} / D=21$.

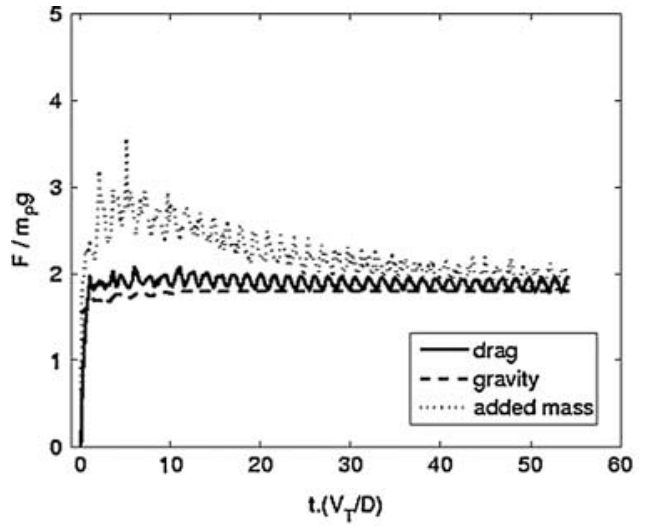

(a)

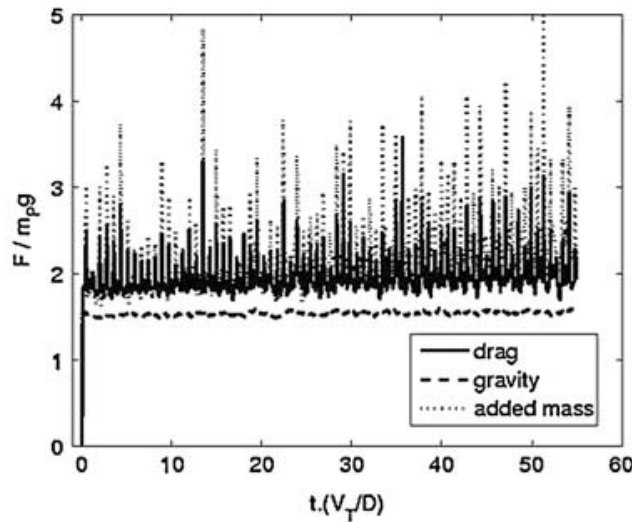

(b)

Fig. 6 -Evolution of the forces acting on particles $\left(\alpha=17 \mathrm{pct} ; \rho_{p}=0.36 \rho_{l}\right):(a) \operatorname{Re}_{p}=5$ and $(b) \operatorname{Re}_{p}=10^{-4}$. The forces are scaled by the weight of a particle. 
period of oscillation is found to be $1.54 \mathrm{D} / V_{T}$, which is very close to the period of crossing of the domain by a bubble the value of which is $H / V_{T}=(2 / 3 \alpha)^{1 / 3} D / V_{T} \approx$ $1.57 \mathrm{D} / V_{T}$, in the case of $\alpha=17 \mathrm{pct}$ (the difference between the two periods is less than 2 pct). Figure $6(\mathrm{~b})$ shows the evolution of the forces in the case of small particles $\left(\operatorname{Re}_{p}=10^{-4}\right)$. The evolution is roughly the same as that displayed in Figure 6(a), but the amplitude of drag and added-mass oscillations is much larger. In addition, the oscillation frequency is higher, about twice the crossing frequency of the domain by the bubble. This explains why the gravitational force does not exhibit such oscillations since it is independent of the liquid velocity. These oscillations enlighten the ability of particles to adapt to the flow. Indeed, calculating the particle Stokes number $\mathrm{St}=\left(\rho_{p}+\rho_{l} / 2\right) d_{p}^{2} V_{T} / 9 \mu_{l} D$, we find $\mathrm{St}=0.74$ (respectively, $5.5 \times 10^{-4}$ ) for particles with $\mathrm{Re}_{p}$ equal to 5 (respectively, $10^{-4}$ ). Not unlikely, the Stokes number is of $O(1)$ in the case of big particles, whereas it is much less than 1 in the case of small particles. This explains why the big (respectively, small)

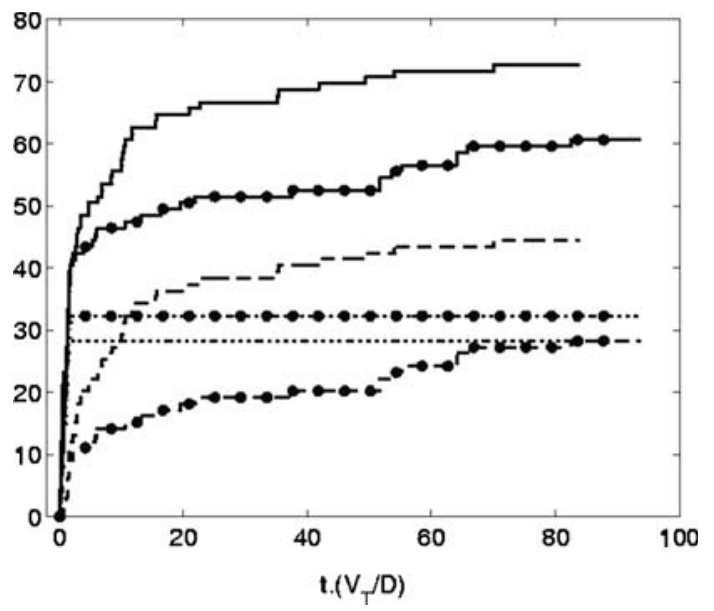

Fig. 7-Influence of the size of particles on efficiencies $(\alpha=11 \mathrm{pct}$, $\left.\rho_{p}=0.36 \rho_{l}\right)$. (-) $E_{\text {coll }}+E_{\text {entr }}$; ( - - - - ) $E_{\text {entr }} ;(\ldots ..) E_{\text {coll }}$; and without symbols: $\operatorname{Re}_{p}=5$. With symbols: $\operatorname{Re}_{p}=10^{-4}$. The efficiencies are indicated in percents. particles are more sensitive to the slow (respectively, rapid) timescales of the flow.

A quantitative effect of the particle size is plotted in Figure 7, through the time evolution of $E_{\text {coll }}, E_{\text {entr }}$ and $\left(E_{\text {coll }}+E_{\text {entr }}\right)$ in the case where $\alpha=11$ pct and $\rho_{p}=$ $0.36 \rho_{l}$. The first set (without symbols) corresponds to big particles, while the second (with symbols) is for small particles. A slight increase in the encounter efficiency (roughly 5 pct) and a strong decrease in the entrainment efficiency (roughly $20 \mathrm{pct}$ ) are observed when going from high- $\mathrm{Re}_{P}$ to low- $\mathrm{Re}_{P}$ particles. Note, however, that the time evolution is similar. The overall efficiency is higher for large particles.

\section{B. Influence of the Gas Volume Fraction}

Figure 8 shows the temporal evolution of the encounter, entrainment, and overall efficiencies, depending on the gas volume fraction ( $\alpha=0.7$ to $17 \mathrm{pct})$, in the case $\rho_{p}=0.36 \rho_{l}$ and $\operatorname{Re}_{p}=5$. The encounter efficiency increases rapidly at early times and then becomes constant at a time $t^{\text {coll }}$. This time decreases as the gas volume fraction increases, because the distance to be crossed by a given bubble to reach the initial position of the preceding bubble (i.e., the bubble located just above it) is smaller for a high volume fraction. Asymptotically, $t^{\text {coll }}=0$ for $\alpha=1$ and $t^{\text {coll }}=\infty$ for $\alpha=0$. In Figure 9 , we plot the evolution of this characteristic

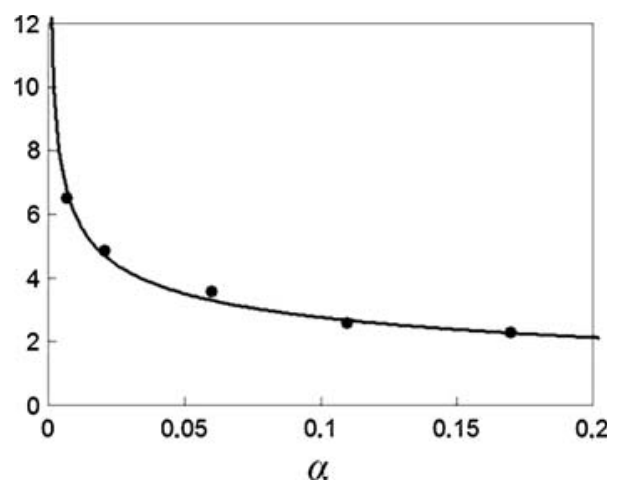

Fig. 9-Evolution of $t^{\text {coll }} V_{T} / D$ with $\alpha$. The solid line corresponds to the fit $f(\alpha)=(1-\alpha)^{0.32} / \alpha^{0.32}$.

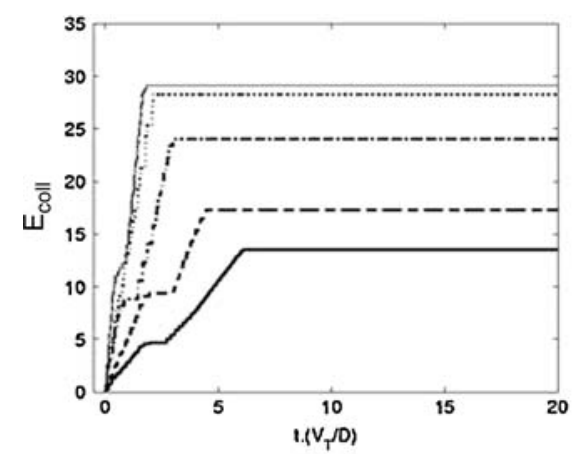

(a)

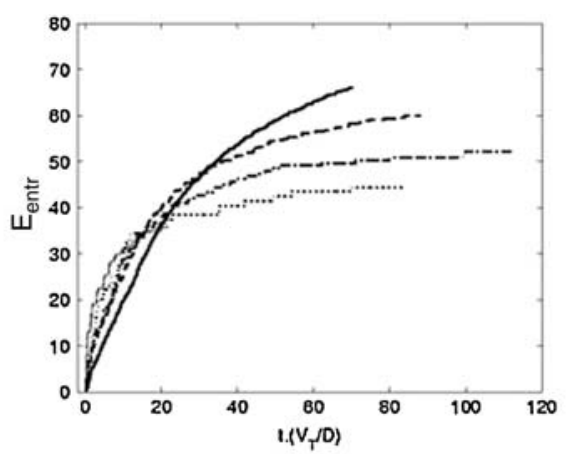

(b)

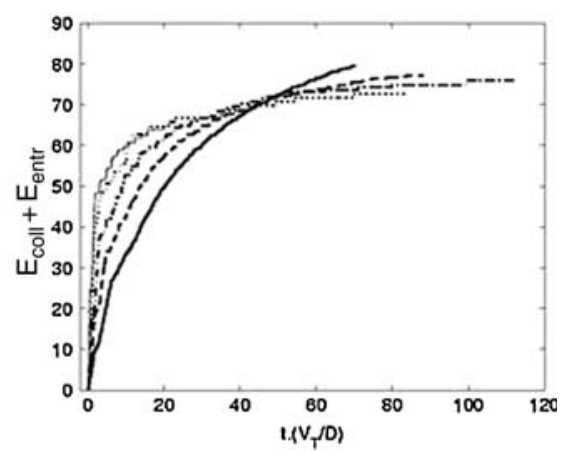

(c)

Fig. 8-Influence of the void fraction on efficiencies: temporal evolution of $(a) E_{\text {coll }}$ and $(b) E_{\text {entr }} ;(c)\left(E_{\text {coll }}+E_{\text {entr }}\right)\left(\rho_{p}=0.36 \rho_{l} ;\right.$ Re $\left.p=5\right)$. $(-)$ $\alpha=0.7$ pct; $(-\ldots-) \alpha=2.1$ pct; $(-\cdots \cdots) \alpha=6$ pct; $(\cdots) \alpha=11$ pct; and $(-) \alpha=17$ pct. Efficiencies are indicated in percents. 
encounter time $t^{\text {coll }} V_{T} / D$ vs the volume fraction $\alpha$. We draw the function $(1-\alpha)^{n} / \alpha^{n}$, and vary the exponent $n$ so as to fit the computational result. We find that $t^{\text {coll }}$ evolves as $(1-\alpha)^{0.32} / \alpha^{0.32}$. At longer times $\left(t>t^{\text {coll }}\right)$, the encounter efficiency is constant. The final value of $E_{\text {coll }}$ grows with the volume fraction. For example, $E_{\text {coll }}$ is twice as high (29 instead of 13 pct) for $\alpha=17$ pct than for $\alpha=0.7$ pct. This result is due to the confinement effects that prevent the particles from getting away from the bubble surface. The variations of $E_{\text {coll }}$ with the volume fraction, the particulate Reynolds number, and the ratio between the particle density and the liquid density are discussed in Section III-E.

The evolution of the entrainment efficiency $E_{\text {entr }}$ shown in Figure 8(b) is quite different from the evolution of the encounter efficiency. Indeed, $E_{\text {entr }}$ is found to increase regularly with time. It grows faster for a high volume fraction at early times than for a low volume fraction $\left(0<t V_{T} / D<20\right)$. Also, the increase of $E_{\text {entr }}$ is faster for a low value of $\alpha$. For $20<t V_{T} / D<60, E_{\text {entr }}$ increases by 9 pct for $\alpha=11$ pct and by 22 pct for $\alpha=0.7$ pct. This unexpected result can be explained by looking at the particle dynamics at longer times $\left(t V_{T} /\right.$ $D>20)$. Figure 10 shows the distribution of the solid particles at $t V_{T} / D=60$ in cases $\alpha=0.7 \mathrm{pct}$ and $\alpha=11$ pct. The closed (respectively, opened) circle is assigned to rising (respectively, falling) particles. We also plotted isovalues of the liquid vertical velocity,

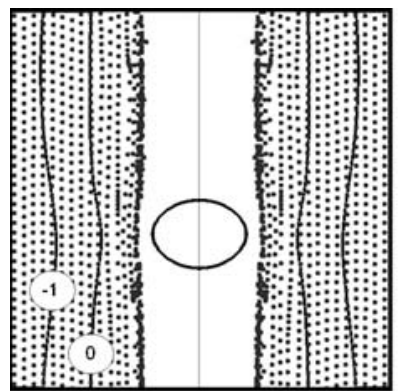

(a)

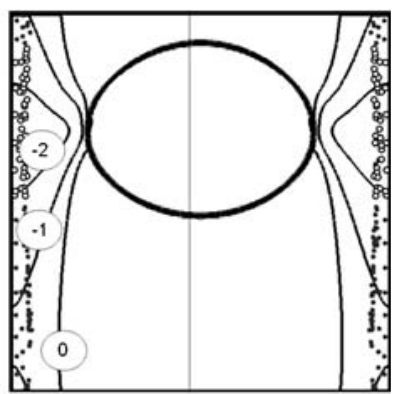

(b)
Fig. 10-Particles distribution at $t V_{T} / D=60:(a) \alpha=0.7$ pct and (b) $\alpha=11$ pct $\left(\rho_{p}=0.36 \rho_{i} ; \operatorname{Re}_{p}=5\right)$. The bubble is at the center of the picture and rises vertically. The solid lines are isovalues of $U_{l}$ $U_{p}\left(U_{l}\right.$ is the local vertical liquid velocity and $U_{p}$ is the sedimentation velocity of the particles). The particles corresponding to closed (respectively, opened) circles are going up (respectively, down). scaled by the sedimentation velocity of the particles $U_{p}=\left(\rho_{l}-\rho_{g}\right) g d_{p}^{2} / 18 \mu_{l}$. In both cases, the particles are located outside the bubble wake, as was already observed in Section III-A. In addition, we see in Figure 10(a) that all particles are rising, whereas in Figure 10(b), the particles located near the bubble equator are falling down. Far from the bubble, the motion of the particles mostly results from the competition between gravitational and drag forces. When gravity is larger (respectively, lower) than drag, the particles are rising (respectively, falling down). Figure 10 (a) shows that $U_{l} \approx-U_{p}$ in the vicinity of the lateral boundaries, whereas $U_{l} \approx-2 U_{p}$ in Figure $10(\mathrm{~b})$, because of confinement effects. In the latter case, the drag force is about four times bigger (since the drag is proportional to the square of the downward liquid velocity $U_{l}$ ), so that the gravitational force turns out to be smaller than the drag force. As a consequence, particles are falling down. This downward motion is responsible for the average evolution of $E_{\text {entr }}$ and may explain the larger increase of the efficiency at longer times when the gas volume fraction is low.

The evolution of the overall efficiency $\left(E_{\text {coll }}+E_{\text {entr }}\right)$ displayed in Figure 8(c) is a consequence of the contribution of both encounter and entrainment effects. Thus, $\left(E_{\text {coll }}+E_{\text {entr }}\right)$ is larger for a high gas volume fraction at early times and turns to be larger for a low volume fraction at longer times.

\section{Influence of the Particle Density}

To determine the influence of the particle density on the flotation process, we keep the particle size constant $\left(\operatorname{Re}_{p}=5\right)$ and vary the density $\rho_{p}$ from $0.1 \rho_{l}$ to $\rho_{l}$. Figure 11 shows the distribution of particles at $t V_{T}$ $D=65.7$ for different sets of particles. In all cases, the particles lie outside the bubble wake. By comparing Figure 11 with Figure 5, we can conclude that the migration of particles outside the bubble wake is mainly due to the size of the particles rather than to their density. In addition, the distribution of particles is roughly the same for all sets of particles. Note that the heavier particles lie closer to the bubble equator and are more dispersed in the region separating the bubble wake from the lateral boundaries. By looking at the average efficiencies (Figure 12), we observe that $E_{\text {coll }}$ increases with the particle density, and that $E_{\text {entr }}$ and $\left(E_{\text {coll }}+\right.$ $E_{\text {entr }}$ ) decrease when $\rho_{p}$ increases.

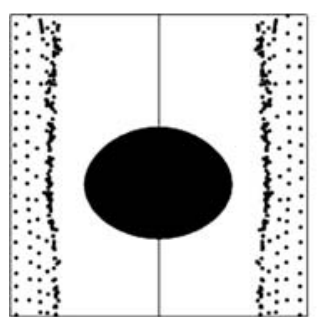

(a)

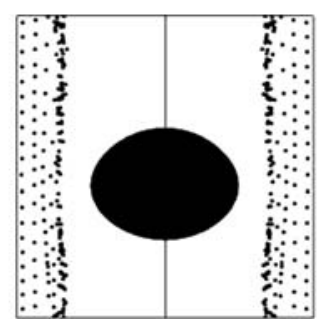

(b)

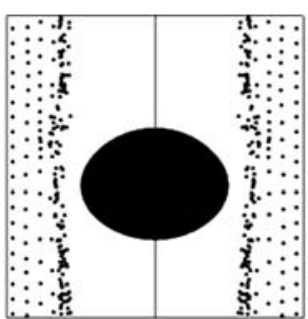

(c)

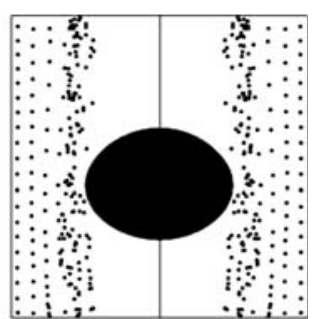

(d)

Fig. 11 - Influence of the particle density $\left(t V_{T} / D=65.7 ; \alpha=6\right.$ pct; and $\left.\operatorname{Re}_{p}=5\right):(a) \rho_{p}=0.1 \rho_{l} ;(b) \rho_{p}=0.36 \rho_{i} ;(c) \rho_{p}=0.86 \rho_{l} ;$ and $(d) \rho_{p}=$ $\rho_{l}$. 


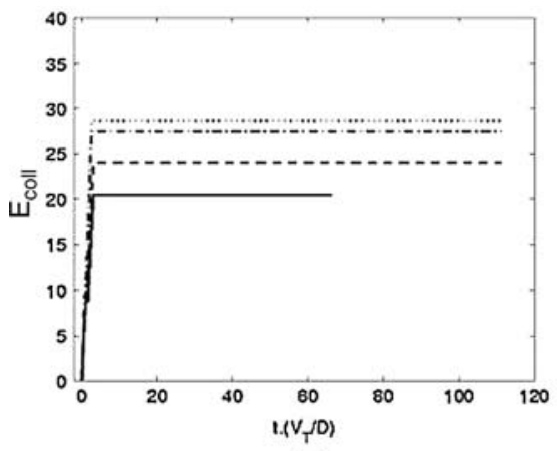

(a)

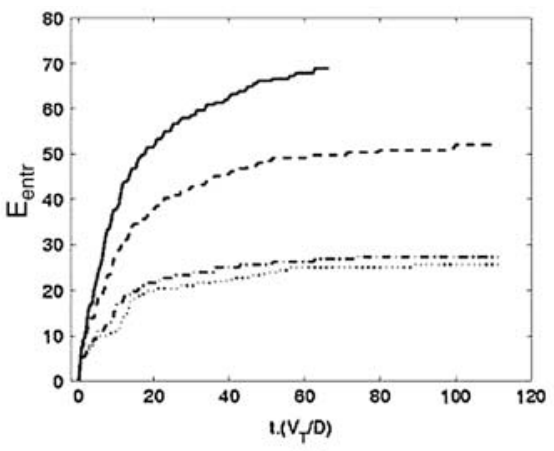

(b)

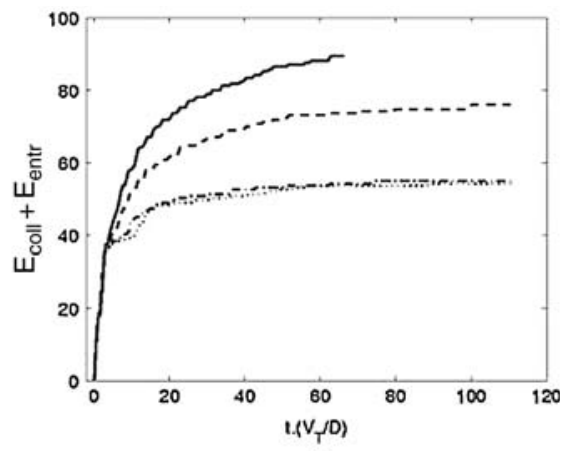

(c)

Fig. 12-Influence of the mass of particles on efficiencies: temporal evolution of $(a) E_{\text {coll }} ;(b) E_{\text {entr }} ;(c)\left(E_{\text {coll }}+E_{\text {entr }}\right)\left(\alpha=6\right.$ pct; Re $\left.{ }_{p}=5\right)$. $(-)$

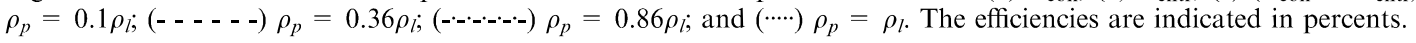
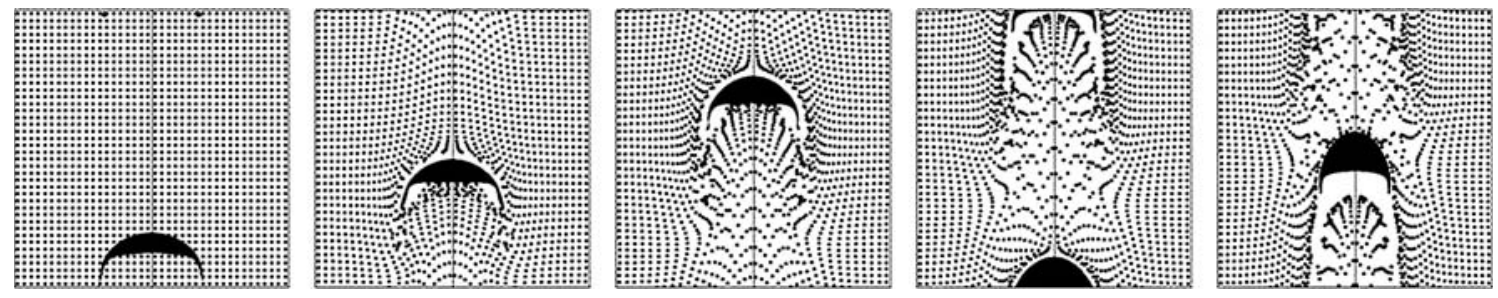

Fig. 13-Evolution of the spatial distribution of particles $\left(\alpha=0.7\right.$ pct; $\rho_{p}=0.36 \rho_{l}$; and $\left.\operatorname{Re}_{p}=5\right)$. The time interval between two successive views is $t V_{T} / D=1.9$.

\section{Influence of the Bubble Shape}

This section is aimed at describing some features that characterize the influence of the bubble shape on the motion of the particles. As mentioned earlier, big particles get away from the bubble wake. We can wonder whether this phenomenon is sensitive to the bubble shape. We performed a computation of the situation corresponding to $\alpha=0.7$ pct, $\operatorname{Re}_{p}=5$, and $\rho_{p}=0.36 \rho_{l}$ by choosing the properties of the liquid so that $\mathrm{Bo}=10^{2}$ and $\mathrm{Mo}=10^{-3}$. The expected shape of an isolated bubble within the corresponding liquid is a spherical cap, and the bubble Reynolds number based on the rise velocity is of $O\left(10^{2}\right)$. Figure 13 shows the particle distribution at various times. We see that no migration of particles away from the bubble wake occurs, at least at early times, in contrast to the case of the spheroidal bubbles. Particles sitting behind the bubble skirt are entrained at about the same velocity as is the bubble. Figure 14 compares the wake structure behind a spherical cap bubble with that behind a spheroidal bubble. The difference observed in the particle migration leads us to conclude that the bubble shape and, therefore, the wake structure play a crucial role in the migration process. Figure 15 compares the temporal evolution of $E_{\text {coll }}, E_{\text {entr }}$, and $\left(E_{\text {coll }}+E_{\text {entr }}\right)$. A first noticeable point is the low value of the encounter efficiency obtained with spherical cap bubbles. This result can be explained by the observation of a thin region in the liquid around the bubble surface where there are no particles (Figure 13), even though the film thickness decreases in time. A second important point is the large increase of $E_{\text {entr }}$ due to the motion of particles

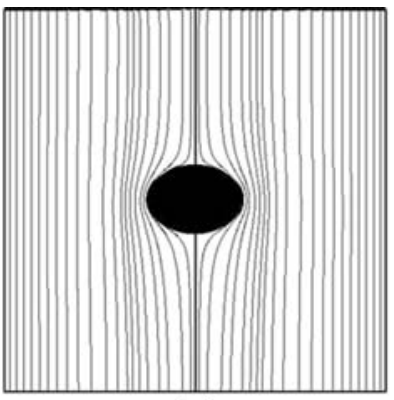

(a)

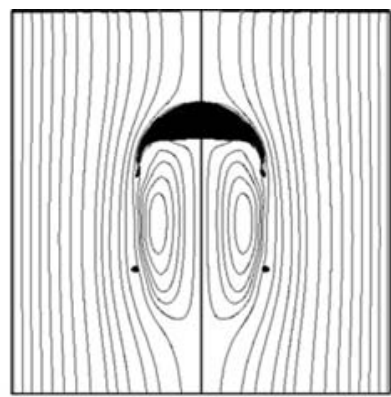

(b)
Fig. 14-Bubble shape and streamlines in the liquid in a frame of reference moving with the bubble: $(a)$ Bo $=1$ and $(b)$ Bo $=100$.

in the spherical cap wake. Note that the bubble shape does not reach a steady state, because the bubble interacts with the wake induced by the preceding bubble. Therefore, the rising speed of the bubble is not strictly constant. Nevertheless, this example shows how sensitive the motion of particles and, therefore, the flotation process is to the shape of the collecting bubbles.

\section{E. Encounter Efficiency: $E_{\text {coll }}=f\left(\alpha, R e_{p}, \rho_{p} / \rho_{l}\right)$}

We now discuss the dominant parameters controlling the encounter phenomenon. We vary the void fraction, and the size and density of particles. The evolution of the encounter efficiency $E_{\text {coll }} v s$ the gas volume fraction is plotted in Figure 16. The $E_{\text {coll }}$ increases with the gas volume fraction as $\alpha^{0.25}$. Figure 17 shows the evolution of $E_{\text {coll }}$ with the particle density and size. We see that the 


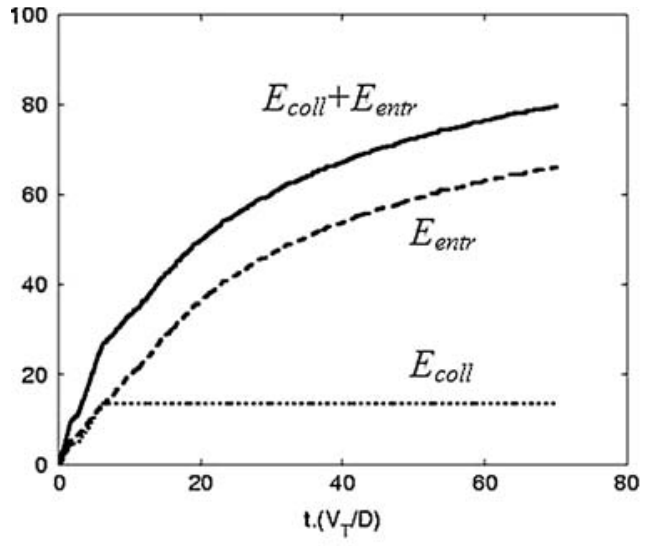

(a)

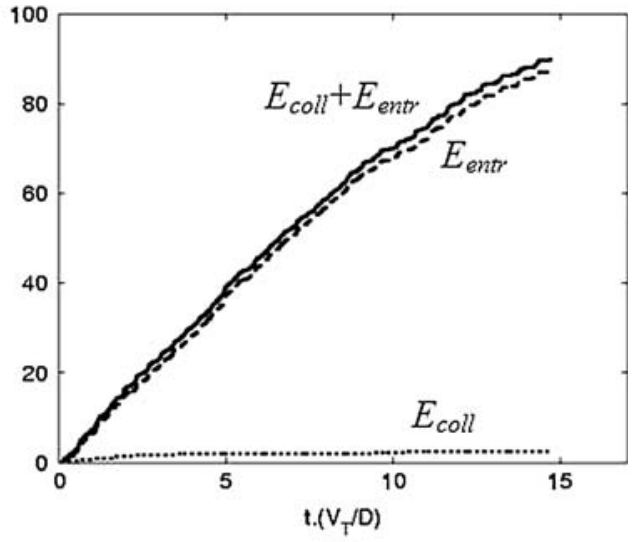

(b)

Fig. 15-Influence of the bubble shape on efficiencies $\left(\alpha=0.7 \mathrm{pct}, \rho_{p}=0.36 \rho_{l}\right.$, and $\left.\operatorname{Re}_{p}=5\right)$. (一) $E_{\text {coll }}+E_{\text {entr }} ;(---\cdots) E_{\text {entr }} ;(\ldots \ldots) E_{\text {coll }}$ : (a) $\mathrm{Bo}=1$ and $(b) \mathrm{Bo}=100$. The efficiencies are indicated in percents.

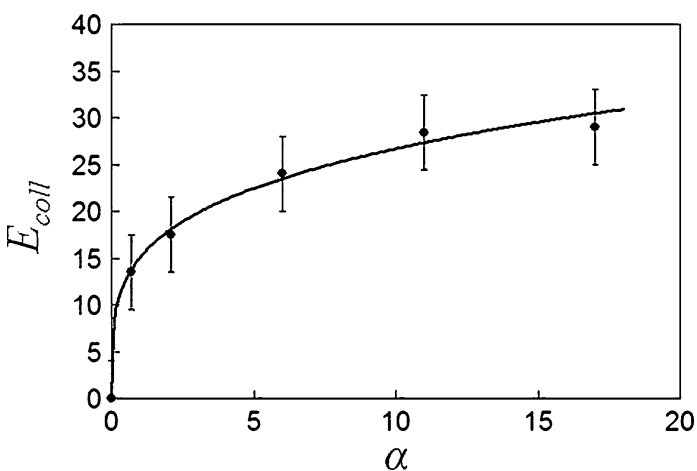

Fig. 16-Evolution of the encounter efficiency (in percents) with the gas volume fraction $\left(\rho_{p}=0.36 \rho ; \operatorname{Re}_{p}=5\right)$. The symbols refer to numerical results; the line corresponds to $E_{\text {coll }}=15 \alpha^{0.25}$. The error bars are due to the influence of the initial position of the bubble with respect to the upper boundary of the computational domain.

results nicely collapse when $E_{\text {coll }}$ is normalized by $\alpha^{0.25}$. The encounter efficiency is found to increase almost linearly with the particle density. Its evolution with the particle size is less straightforward. The efficiency is found to increase slightly with $\operatorname{Re}_{p}$ up to $10^{-2}$ and to decrease for higher Reynolds numbers.

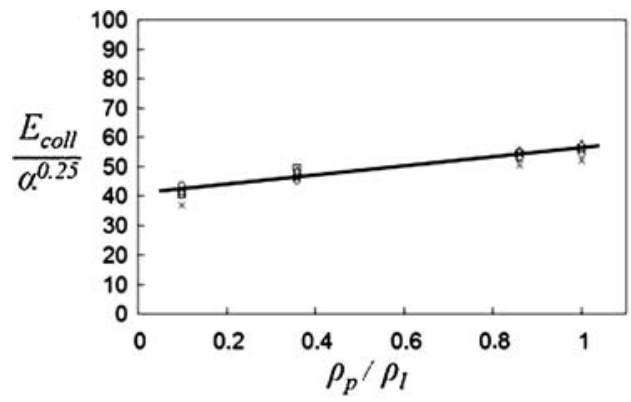

(a)

\section{CONCLUSIONS}

This study dealt with the dispersion of small, solid particles in a liquid the agitation of which is driven by the rise of a homogeneous swarm of bubbles. We simulated both the two-phase flow (with deforming bubbles) and the motion of solid particles (through a Lagrangian tracking procedure). The evolution of the spatial distribution of particles, the encounter efficiency, and the entrainment efficiency were determined as a function of the gas volume fraction and of the relative size and relative density of the particles. We investigated a wide range of parameters, namely $\alpha=0.7$ through 17 pct, $\rho_{p}=0.1 \rho_{l}$ through $\rho_{l}$, and $\mathrm{Re}_{p}=10^{-4}$ through 5. The influence of the bubble shape and the influence of the model of forces driving the particle motion were also considered. The main results may be summarized as follows.

1. We observed a migration of particles away from the bubble wake. This migration is typical of big particles for which inertial effects are significant.

2 . The encounter efficiency increases with the gas volume fraction (as $\alpha^{0.25}$ ) and the particle density, but decreases with the particle size, at least for particle Reynolds numbers larger than $10^{-2}$.

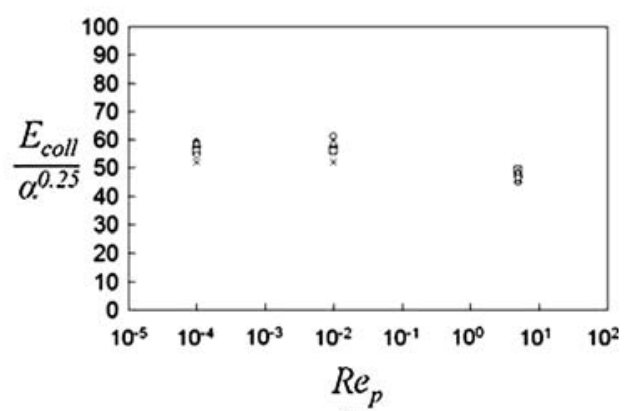

(b)

Fig. 17-Evolution of the encounter efficiency with $(a)$ the relative mass of the particle and $(b)$ the particle size. The symbols refer to numerical results: $(\diamond) \alpha=0.7$ pct, $(\times) \alpha=2.1$ pct, $(\Delta) \alpha=6$ pct, $(\square) \alpha=11$ pct, and $(\bigcirc) \alpha=17$ pct. The solid line is a linear fit. 
3. The entrainment efficiency increases (respectively, decreases) with the gas volume fraction at early (respectively, long) times, and increases with the particle size.

4. The shape and wake structure of the bubbles have a crucial influence on the motion of small particles and on the flotation process.

5. The shear-induced lift force has a weak influence on the flotation process in the situation we considered here (Appendix).

Overall, we believe that this work provides useful data for the validation of models aimed at predicting the collision and entrainment efficiencies for a wide range of void fractions and sizes of particles. In addition, we showed that the shape of large bubbles can have a significant impact on flotation efficiencies. This suggests that additional work is needed to take into account the effect of the nonspherical shapes of large bubbles.

This work could be extended in the following ways:

1. by changing the shape of the bubbles; and

2 . by considering nonhomogeneous bubble swarm (i.e., performing fully three-dimensional computations), allowing us to take into account nonrectilinear bubble trajectories and bubble break-up and coalescence in the flotation process.

\section{APPENDIX}

\section{Influence of added-mass and shear-induced lift forces}

An important issue is to find out how the force models on the right side of Eq. [3] influence the results involving the particle motion and the efficiency statistics. Some aspects of the role played by the gravity, drag, and added-mass forces were already presented in Section III-A. However, we can still question the influence of the added-mass effects on the migration phenomenon. Figure 18 compares the particles distribution when added-mass effects are taken into account. When the added-mass force is switched off, some particles remain in the bubble wake (Figure 18(a)). In contrast, when added-mass effects are taken into account, no particle remains in the bubble wake (Figure 18(b)). Therefore, it turns out that added-mass effects are part of the origin of the migration phenomenon. We could also wonder whether including the shear-induced lift force would have changed the results. To check this point, we performed a computation in which the lift force was included (Figure 18(c)). Following McLaughlin's theoretical result ${ }^{[4]}$ valid for particles moving at a low but finite Reynolds number in a pure shear flow, an extra term $F_{L}$ should be added to the right side of Eq. [3], namely

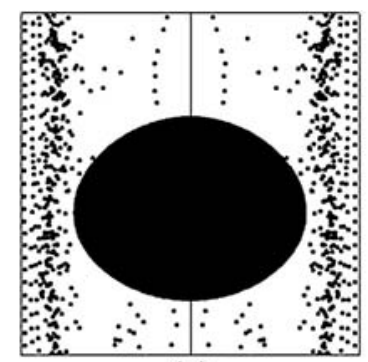

(a)

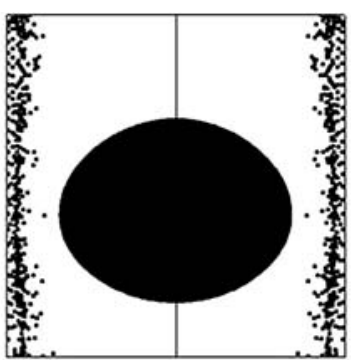

(b)

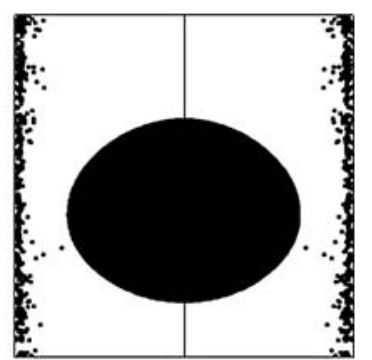

(c)

Fig. 18-Influence of added-mass and shear-induced lift forces on the particle distribution, $(a)$ without both added-mass and shear-induced lift and $(b)$ with added-mass included but without shear-induced lift; and $(c)$ with both added-mass and shear-induced lift $\left(t V_{T} / D=28.5 ; \alpha=17\right.$ pct; $\rho_{p}=0.36 \rho_{l}$; and $\left.\operatorname{Re}_{p}=5\right)$.

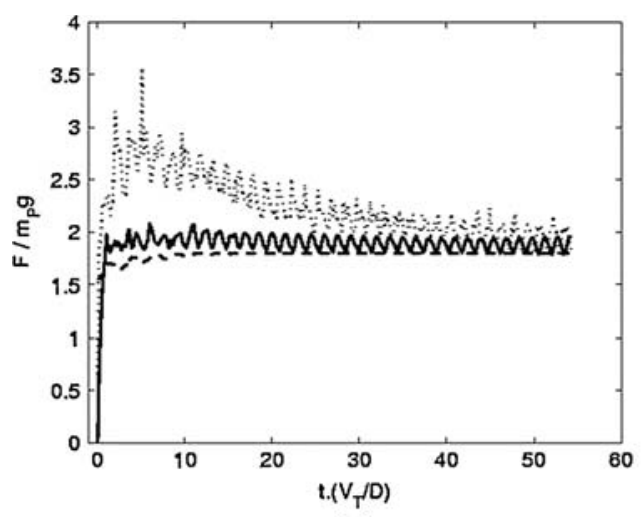

(a)

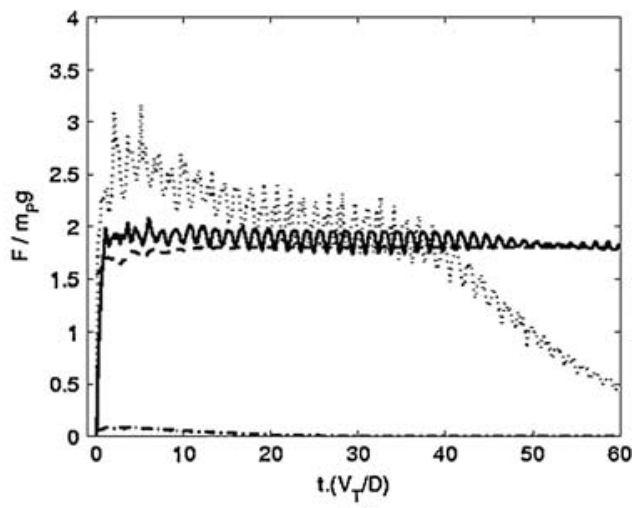

(b)

Fig. 19-Evolution of the averaged forces acting on particles $\left(\alpha=17\right.$ pct; $\rho_{p}=0.36 \rho_{l}$; and $\left.\operatorname{Re}_{p}=5\right)$ : $(a)$ without shear-induced lift and $(b)$ including the shear-induced lift model of Eqs. [5a] and [5b]. (....) Added-mass force; (-) drag; (- - - - - -) Archimedes force; and (-.--..--) shearinduced lift. All forces are normalized by the weight of the particle. 


$$
F_{L}=m_{f} C_{L}(U-V) \times \operatorname{rot}(U-V)
$$

with

$$
\begin{aligned}
& C_{L}=\frac{9}{\pi^{2}} \frac{2.255}{\sqrt{\mathrm{Re}_{p} \mathrm{Sr}}}\left(1+0.2 \frac{\mathrm{Re}_{p}}{\mathrm{Sr}}\right)^{-3 / 2} \\
& \text { with } \mathrm{Sr}=\frac{2 R|\operatorname{rot}(U-V)|}{|U-V|}
\end{aligned}
$$

Strictly speaking, this model for the shear-induced lift force is only valid under the assumptions $\operatorname{Re}_{p}<<1$ and $(\mathrm{Sr} / \mathrm{Re})^{1 / 2}<<1$. However, extensive direct numerical simulations ${ }^{[35]}$ revealed that it provides a reasonable estimate of the shear-induced lift force up to $\operatorname{Re}_{p} \approx 5$. Present computations indicate that the particle distribution is very similar whether the shear-induced lift force model is included or not (Figure 18). Figure 19 compares the evolution of the averaged forces acting on the particles, in both cases. Clearly, the presence of the shear-induced lift force only affects the added-mass force at long times and leaves the other contributions unchanged. Note that the intensity of the shear-induced lift force is one order of magnitude smaller than that of the other forces. Therefore, we can conclude that shearinduced lift effects do not play a significant role in the

\begin{tabular}{|c|c|}
\hline$\rho$ & local density $\left(\mathrm{kg} / \mathrm{m}^{3}\right)$ \\
\hline$\mu$ & $\begin{array}{l}\text { local dynamic viscosity }(\mathrm{kg} / \\
\mathrm{m} / \mathrm{s})\end{array}$ \\
\hline$C_{M}$ & $\begin{array}{l}\text { added mass coefficient (here, } \\
C_{M}=1 / 2 \text { ) }\end{array}$ \\
\hline$D$ & bubble diameter $(\mathrm{m})$ \\
\hline$d_{p}$ & particle diameter (m) \\
\hline$E_{\mathrm{coll}}$ & encounter efficiency \\
\hline$E_{\text {entr }}$ & entrainment efficiency \\
\hline$g$ & $\begin{array}{l}\text { gravitational acceleration } \\
\left(\mathrm{m} / \mathrm{s}^{2}\right)\end{array}$ \\
\hline$H$ & $\begin{array}{l}\text { height of the computational } \\
\text { domain }(\mathrm{m})\end{array}$ \\
\hline$m_{f}$ & $\begin{array}{l}\text { mass of the liquid of same } \\
\text { volume as the particle }(\mathrm{kg})\end{array}$ \\
\hline$m_{p}$ & mass of the particle $(\mathrm{kg})$ \\
\hline$n$ & $\begin{array}{l}\text { unit vector normal to the } \\
\text { interface }\end{array}$ \\
\hline$P$ & pressure $(\mathrm{Pa})$ \\
\hline$U$ & $\begin{array}{l}\text { local velocity (at the particle } \\
\text { location for Eq. [3], m/s) }\end{array}$ \\
\hline$U_{l}$ & $\begin{array}{l}\text { local velocity in the liquid } \\
(\mathrm{m} / \mathrm{s})\end{array}$ \\
\hline$V$ & particle velocity $(\mathrm{m} / \mathrm{s})$ \\
\hline$V_{T}$ & $\begin{array}{l}\text { bubble terminal velocity }(\mathrm{m} / \\
\mathrm{s})\end{array}$ \\
\hline$\mu_{g}$ & $\begin{array}{l}\text { dynamic viscosity of the gas } \\
(\mathrm{kg} / \mathrm{m} / \mathrm{s})\end{array}$ \\
\hline$\mu_{l}$ & $\begin{array}{l}\text { dynamic viscosity of the } \\
\text { liquid }(\mathrm{kg} / \mathrm{m} / \mathrm{s})\end{array}$ \\
\hline
\end{tabular}
situation considered in this article.

\section{NOMENCLATURE}

$\rho_{g}$
$\rho_{l}$
$\rho_{p}$
$\sigma$
$\delta_{I}$
$\alpha=2 D^{3} / 3 H^{3}$
Вo $=\rho_{l} g D^{2} / \sigma$
Mo $=g \mu_{l}^{4} / \rho_{l} \sigma^{3}$
$U_{p}=\left(\rho_{l}-\rho_{p}\right) g d_{p}^{2} / 18 \mu_{l}$

density of the gas $\left(\mathrm{kg} / \mathrm{m}^{3}\right)$ density of the liquid $\left(\mathrm{kg} / \mathrm{m}^{3}\right)$ density of the particles $(\mathrm{kg} /$ $\mathrm{m}^{3}$ ) surface tension between the gas and the liquid $(\mathrm{N} / \mathrm{m})$ surface delta function volume fraction Bond number Morton number Stokes sedimentation velocity of a solid particle

\section{REFERENCES}

1. O.N. Cardoso, T. Sotto Mayor, A.M.F.R. Pinto, and J.B.L.M Campos: Chem. Eng. Sci., 2003, vol. 58, pp. 4159-72.

2. W. Wang, Z. Zhou, K. Nandakumar, Z. Xu, and J.H. Masliyah: Int. J. Miner. Process., 2003, vol. 68, pp. 47-69.

3. D. Reay and G.A. Ratcliff: Can. J. Chem. Eng., 1975, vol. 53, pp. 481-86.

4. G.L. Collins and G.J. Jameson: Chem. Eng. Sci., 1976, vol. 31, pp. 985-91.

5. G.L. Small, S.R. Grano, J. Ralston, and N.W. Johnson: Miner. Eng., 1997, vol. 10, pp. 1-15.

6. Y. Hu, G. Qiu, and J.D. Miller: Int. J. Miner. Process., 2003, vol. 70, pp. $157-70$.

7. J.P. Anfruns and J.A. Kitchener: Trans. Inst. Min. Metall., 1977, vol. 86 , pp. 9-19.

8. D. Hewitt, D. Fornaseiro, and J. Ralston: J. Chem. Soc., Faraday Trans., 1995, vol. 91, pp. 1997-2001.

9. Z. Dai, S. Dudhin, D. Fornaseiro, and J. Ralston: J. Colloid Interface Sci., 1998, vol. 197, pp. 275-92.

10. Z. Dai, D. Fornaseiro, and J. Ralston: J. Chem. Soc., Faraday Trans., 1998, vol. 94, pp. 1983-87.

11. Z. Dai, D. Fornaseiro, and J. Ralston: J. Colloid Interface Sci., 1999, vol. 217, pp. 70-76.

12. J. Ralston, S.S. Dukhin, and N.A. Mishchuk: Int. J. Miner. Process., 1999, vol. 56, pp. 207-56.

13. A.V. Nguyen, G.M. Evans, J. Nalaskowski, J.D. Miller, and H.J. Butt: Int. J. Miner. Process., 2003, vol. 72, pp. 215-25.

14. A.V. Nguyen, G.M. Evans, J. Nalaskowski, and J.D. Miller: Exp. Therm. Fluid Sci., 2004, vol. 28, pp. 387-94.

15. K.L. Sutherland: J. Phys. Chem., 1948, vol. 52, pp. 394-425.

16. M.E. Weber and D. Paddock: J. Colloid Interface Sci., 1983, vol. 94, pp. 328-35.

17. J. Ralston, D. Fornaseiro, and R. Hayes: Int. J. Miner. Process., 1999, vol. 56, pp. 133-64.

18. A.V. Nguyen and G.M. Evans: Int. J. Multiphase Flow, 2002, vol. 28, pp. $1369-80$.

19. C.M. Phan, A.V. Nguyen, J.D. Miller, G.M. Evans, and G.J. Jameson: Int. J. Miner. Process., 2003, vol. 72, pp. 239-54.

20. E. Mileva and L. Nikolov: J. Colloid Interface Sci., 2003, vol. 265, pp. 310-19.

21. V. Sarrot, P. Guiraud, and D. Legendre: Chem. Eng. Sci., 2005, vol. 60 , pp. 6107-17.

22. A.V. Nguyen, J. Ralston, and H.J. Schulze: Int. J. Miner. Process., 1998, vol. 53, pp. 225-49.

23. J. Ralston and S.S. Dukhin: Colloids Surf., A, 1999, vol. 151, pp. 3-14.

24. J. Ralston: J. S. Afr. Inst. Min. Metall., 1999, Jan.-Feb., vol. 99 , pp. 27-34.

25. R.H. Yoon: Int. J. Miner. Process., 2000, vol. 58, pp. 129-43.

26. A.V. Nguyen: Int. J. Miner. Process., 1998, vol. 55, pp. 73-86.

27. F. Bloom and T.J. Heindel: Chem. Eng. Sci., 2002, vol. 57, pp. 2467-73.

28. L. Wang, H.G. Lee, and P. Hayes: ISIJ Int., 1996, vol. 36, pp. 7-16.

29. L. Zhang, J. Aoki, and B.G. Thomas: Metall. Mater. Trans. B, 2006, vol. 37B, pp. 361-79.

30. B.V. Derjaguin and S.S. Dukhin: Trans. Inst. Min. Metall., 1960, vol. 70 , pp. $221-46$. 
31. J.U. Brackbill, D.B. Kothe, and C. Zemach: J. Comput. Phys., 1992 , vol. 100 , pp. $335-54$.

32. T. Bonometti and J. Magnaudet: Phys. Fluids, 2006, vol. 18, p. 052102.

33. R. Clift, J.R. Grace, and M.E. Weber: Bubbles, Drops and Particles, Academic Press, New York, NY, 1978, pp. 111-13.
34. J.B. McLaughin: J. Fluid Mech., 1991, vol. 224, pp. 261-74.

35. D. Legendre and J. Magnaudet: J. Fluid Mech., 1998, vol. 368, pp. $81-126$. 